\title{
Awareness and practice of dual contraception among female tertiary institution students in Ibadan, Nigeria
}

This article was published in the following Dove Press journal:

Open Access Journal of Contraception

24 August 2016

Number of times this article has been viewed

\author{
Oluwasomidoyin Olukemi \\ Bello' \\ Timothy AO Oluwasola ${ }^{1,2}$ \\ Folasade Adenike Bello ${ }^{1,2}$ \\ 'Department of Obstetrics and \\ Gynecology, University College \\ Hospital, ${ }^{2}$ Department of Obstetrics \\ and Gynecology, University of Ibadan, \\ Ibadan, Oyo State, Nigeria
}

Correspondence: Oluwasomidoyin Olukemi Bello

Department of Obstetrics and Gynecology, University College Hospital, PMB 5I I6, Agodi, Ibadan, Oyo State,

Nigeria

Tel +234803 37I I I I6

Email bellodoyin@yahoo.com
Purpose: To determine the knowledge, awareness, and factors associated with the practice of dual contraception among female undergraduates in Ibadan, Nigeria.

Materials and methods: This is a cross-sectional study using a semi-structured self-administered questionnaire to assess the knowledge and practice of dual contraception among female undergraduates in the University of Ibadan and The Polytechnic, Ibadan. A total of 1,200 undergraduate students were interviewed, and data obtained were analyzed with SPSS Version 18.0.

Results: The mean age of the respondents was $22.57 \pm 3.43$ years. Among the respondents, 900 (84.6\%) were unmarried, 871 (77.9\%) have been sexually exposed, 793 (70.9\%) had heard of dual contraception, and 659 (58.9\%) had knowledge of dual contraception. Majority (66.8\%) of the participants used effective contraception, of whom 423 (56.3\%) used condom, while others used other short- or long-term reversible contraception. More than two-thirds $(79.2 \%)$ of the sexually exposed respondents were aware of dual contraception, but only $465(41.6 \%)$ had practiced it. The main sources of information about dual contraception were from friends and radio $(45.3 \%$ and $36.1 \%$, respectively). Those who had multiple sexual partners and early coitarche were more likely to use dual contraception $(P<0.05)$. History of previous sexually transmitted infection (odds ratio $=3.06,95 \%$ confidence interval $[\mathrm{CI}]=2.03-4.62$ ) and unwanted pregnancy (odds ratio $=3.53,95 \% \mathrm{CI}=2.62-4.74$ ) were strongly associated with the use of dual contraception.

Conclusion: Uptake of dual contraception among the students was low. Efforts need to be concentrated on determining and addressing the challenges that are responsible for the lower uptake of dual contraception among female undergraduates who are at higher risk of unwanted pregnancy and sexually transmitted infections. Promotion of consistent use of dual contraception is pertinent in maximizing the benefits of dual contraception in our environment.

Keywords: uptake, dual contraception, pregnancy, sexually transmitted infection

\section{Introduction}

Dual contraception is the use of two contraceptive methods, one of which is a male/ female condom and another is a highly effective contraceptive method to simultaneously prevent pregnancy and sexually transmitted infections (STIs). ${ }^{1}$ Advocacy for its use should be intensified in young women who are more likely to engage in risky sexual activities with resultant effects of increased complications of unwanted pregnancy and STIs.

Several studies have documented increased risk of pregnancy and STIs in young women as a consequence of high rates of sexual activities..$^{2-4}$ This is a major challenge not only to the reproductive health of young women but also to their economic and psychosocial health resulting from associated complications. 
In the recent National Demographic Health Survey for Nigeria, STIs were highest among singles with a prevalence of $15 \%$ and education was positively correlated with reportage of incidence. ${ }^{5}$ Approximately $70 \%$ of women were sexually active by the age of 20 years, while $24 \%$ had had sexual intercourse before the age of 15 years, thereby making the exposure to reproductive health risks highest among this population. ${ }^{5}$ In addition, only $2 \%$ of sexually active women used condom as a form of contraceptive with no documentation of dual contraception. STI has been associated with factors such as early onset of sexual activity, having multiple sexual partners, inconsistent use of barrier methods, and being part of a population with a high index of STIs. ${ }^{6}$

Poor knowledge about contraception and its consistent usage has been found to contribute to the high incidence of unwanted pregnancy and STIs. ${ }^{7}$ In order to reduce the risks and public health problems associated with unwanted pregnancy and STIs, it is important to advocate the use of dual contraception among young women with risky sexual behavior. Therefore, our aim is to explore the knowledge, awareness, and factors associated with the use of dual contraception as a means of preventing both STIs and unwanted pregnancy among female undergraduates in Ibadan, Nigeria.

\section{Materials and methods}

This was a cross-sectional study among female undergraduates conducted in two tertiary educational institutions University of Ibadan and The Polytechnic, Ibadan, located in the Southwestern part of Nigeria. A semi-structured selfadministered questionnaire was used to assess the knowledge, awareness, and practice of dual contraception as well as the factors associated with its use (Supplementary material). The questionnaire was administered to all consenting female students in their various lecture halls in the two institutions studied. A written consent was obtained from all consenting participants before the questionnaire was administered.

We obtained information on their sociodemographic characteristics, knowledge, awareness, and use of dual contraceptives as well as their sexual history. Explanatory variables included demographic data and sexual history. Outcome variables were awareness and use of dual contraception.

A total of 1,200 undergraduate students were interviewed, and data obtained were analyzed with SPSS Version 18 (SPSS Inc., Chicago, IL, USA). Frequencies were generated, and chi-square test was used to check for associations between categorical variables. Level of statistical significance was set at $P<0.05$. Ethical approval was obtained from the Oyo state ethical review committee.

\section{Results}

A total of 1,118 (93.2\%) of the 1,200 questionnaires were satisfactorily returned and analyzed. The mean age of the participants was $22.57 \pm 3.43$ years (range 16-39 years). Of the 1,118 students, $946(84.6 \%)$ were single, $131(11.7 \%)$ were married, and 41 (3.7\%) were cohabiting (Table 1). Almost a third $(325,29.1 \%)$ of the respondents had never heard of dual contraception, even though 871 (77.9\%) were already sexually exposed (Table 2). Of those who were sexually exposed, more than two-thirds $(690,79.2 \%)$ were aware of dual contraception, $659(58.9 \%)$ had the knowledge of dual contraception in preventing both pregnancy and STIs, while only about two-fifths $(465,41.6 \%)$ had practiced its use.

Among the participants, 747 (66.8\%) have used effective contraception before, of whom 423 (56.3\%) used condom, $15(2.0 \%)$ used intrauterine contraceptive device, 87 (11.6\%) used oral contraceptive pills, 18 (2.4\%) used implant, 82 (10.9\%) were on injectable contraception, and 208 (27.7\%) used morning-after sex pills.

Table I Sociodemographic characteristics of subjects

\begin{tabular}{|c|c|c|}
\hline Variables & Frequency & Percent \\
\hline \multicolumn{3}{|c|}{ Age group $(n=1,|| 8)$} \\
\hline $15-19$ & 164 & 14.7 \\
\hline $20-24$ & 688 & 61.5 \\
\hline $25-29$ & 218 & 19.5 \\
\hline $30+$ & 48 & 4.3 \\
\hline Total & 1,118 & 100 \\
\hline \multicolumn{3}{|l|}{ Marital status } \\
\hline Cohabiting & $4 I$ & 3.7 \\
\hline Single & 946 & 84.6 \\
\hline Married & $|3|$ & II.7 \\
\hline Total & 1,118 & 100 \\
\hline \multicolumn{3}{|l|}{ Religion } \\
\hline Islam & 382 & 34.2 \\
\hline Christianity & 706 & 63.1 \\
\hline Traditional & 13 & 1.2 \\
\hline No response & 17 & 1.5 \\
\hline Total & 1,118 & 100 \\
\hline \multicolumn{3}{|l|}{ Tribe } \\
\hline Yoruba & 857 & 76.7 \\
\hline Hausa & 63 & 5.6 \\
\hline Igbo & 138 & 12.3 \\
\hline Others & 60 & 5.4 \\
\hline Total & $\mathrm{I}, \mathrm{I} \mid 8$ & 100 \\
\hline
\end{tabular}

Table 2 Awareness of dual contraception and sexual exposure

\begin{tabular}{lllll}
\hline Variable & \multicolumn{2}{l}{$\begin{array}{l}\text { Awareness of dual } \\
\text { contraceptive }\end{array}$} & Chi square & P-value \\
\cline { 2 - 3 } & Yes (\%) & No (\%) & & \\
\hline Sexually exposed & & & & \\
Yes & $690(79.2)$ & $181(20.8)$ & 131.37 & $<0.01$ \\
No & $103(41.7)$ & $144(58.3)$ & & \\
Total & 793 & 325 & & \\
\hline
\end{tabular}


The most common sources of information on dual contraception were from their friends/colleagues (45.3\%) and radio $(36.1 \%)$ (Table 3$)$. Other sources of information on dual contraception were television (18.5\%), chemist/pharmacy (7.1\%), and health workers $(6.3 \%)$. However, $83.1 \%$ of the participants who have heard of dual contraception have the knowledge of its effectiveness in preventing both pregnancy and STIs.

History of sexual exposure is significantly associated with awareness of dual contraception (odds ratio $[\mathrm{OR}]=5.33$, $95 \%$ confidence interval $[\mathrm{CI}]=3.94-7.20$ ). Majority of them $(77.9 \%)$ have had sexual intercourse. Table 4 shows that the modal age for sexual debut is 15-19 years, and $542(65 \%)$ of them have been sexually active by age 19 years. A total of $152(70 \%)$ of the 217 students who had multiple sexual partners $(>1)$ in the past 12 months practiced dual contraception; however, those respondents who had more than three sexual partners (79.6\%) practiced dual contraception the most. The table further shows that there is a significant association between the number of sexual partners in the past 12 months

Table 3 Knowledge of dual contraception and use of contraception

\begin{tabular}{lll}
\hline Variable & Frequency & Percent \\
\hline Have you heard of dual contraception $(\mathrm{n}=\mathrm{I}, \mathrm{I}$ I8) & & \\
$\quad$ Yes & 793 & 70.9 \\
No & 325 & 29.1 \\
Knowledge of dual contraception & & \\
$\quad$ Yes & 659 & 58.9 \\
No & 459 & 41.1 \\
Source of information ( $\mathrm{n}=793)$ & & \\
Friends/colleagues & 359 & 45.3 \\
Radio & 286 & 36.1 \\
Television & 147 & 18.5 \\
$\quad$ Chemist/pharmacy & 56 & 7.1 \\
Health workers & 50 & 6.3 \\
\hline
\end{tabular}

Note: Having "heard" of dual contraception assessed the respondents' awareness while "knowledge" of dual contraception assessed their information and understanding of dual contraception and its use.

Table 4 Number of sexual partners in the past 12 months, age at coitarche, and practice of dual contraception

\begin{tabular}{|c|c|c|c|c|}
\hline \multirow[t]{2}{*}{ Variable } & \multicolumn{2}{|c|}{$\begin{array}{l}\text { Practice of dual } \\
\text { contraception }\end{array}$} & \multirow[t]{2}{*}{ Chi square } & \multirow[t]{2}{*}{$P$-value } \\
\hline & Yes (\%) & No (\%) & & \\
\hline \multicolumn{5}{|c|}{ Number of sexual partners in the past 12 months $(n=786)$} \\
\hline I & $281(49.4)$ & $288(50.6)$ & 34.659 & $<0.01$ \\
\hline 2 & $113(67.3)$ & $55(32.7)$ & & \\
\hline $3+$ & $39(79.6)$ & $10(20.4)$ & & \\
\hline \multicolumn{5}{|c|}{ Age at first sexual intercourse $(n=833)$} \\
\hline$<15$ years & $10(58.8)$ & $7(4 \mid .2)$ & 18.80 & $<0.01$ \\
\hline $15-19$ years & $320(59.0)$ & $222(41.0)$ & & \\
\hline 20-24 years & $120(45.6)$ & $143(54.4)$ & & \\
\hline $25+$ years & $2(18.2)$ & $9(81.8)$ & & \\
\hline
\end{tabular}

Table 5 Factors associated with dual contraceptive method use

\begin{tabular}{|c|c|c|c|}
\hline Variable & Odds ratio & $P$-value & $95 \% \mathrm{Cl}$ \\
\hline \multicolumn{4}{|l|}{ Marital status } \\
\hline Cohabiting & 1.31 & 0.44 & $0.66-2.59$ \\
\hline Single & 2.17 & 0.04 & $1.03-4.59$ \\
\hline \multicolumn{4}{|l|}{ Married } \\
\hline \multicolumn{4}{|c|}{ Had sexual intercourse in the past 6 months } \\
\hline Yes & 6.12 & $<0.0001$ & $4.54-8.25$ \\
\hline \multicolumn{4}{|l|}{ No } \\
\hline \multicolumn{4}{|l|}{ History of STI } \\
\hline Yes & 3.06 & $<0.05$ & $2.03-4.62$ \\
\hline \multicolumn{4}{|l|}{ No } \\
\hline \multicolumn{4}{|c|}{ History of unwanted pregnancy } \\
\hline Yes & 3.53 & $<0.01$ & $2.62-4.74$ \\
\hline No & & & \\
\hline
\end{tabular}

Abbreviation: STI, sexually transmitted infection.

and practice of dual contraception $\left(\chi^{2}=34.66, P\right.$-value $\left.<0.01\right)$ as well as the age at first sexual intercourse and practice of dual contraception $\left(\chi^{2}=18.80, P\right.$-value $\left.<0.01\right)$.

Overall, 248 (22.2\%) had had unwanted pregnancy, while $112(10 \%)$ had had previous STI. The practice of dual contraception is strongly associated with history of previous STI ( $\mathrm{OR}=3.06,95 \% \mathrm{CI}=2.03-4.62)$ and unwanted pregnancy $(\mathrm{OR}=3.53,95 \% \mathrm{CI}=2.62-4.74)$ as presented in Table 5. Other factors that are significantly associated with the practice of dual contraception include history of multiple sexual partners, having had sexual intercourse in the past 6 months, and earlier age of sexual debut.

\section{Discussion}

This study demonstrated a high level of awareness of dual contraception but a lower level of its knowledge and use among the study population. Although, a similar study done among undergraduates in Tanzania showed that all their study participants were aware of dual contraception with only $41.5 \%$ of the participants using contraception at the time of the study. ${ }^{8}$ Chibwesha et al ${ }^{9}$ also documented low use of dual contraception among contraceptive users in a study among HIV-infected women.

Majority (77.9\%) of the students had had sexual intercourse, with a large number of them $(65 \%)$ being sexually active by the age of 19 years, which is slightly higher than the Tanzanian study where $70.4 \%$ of the participants had been engaged in sexual intercourse, but their mean age at sexual debut was 20 years. ${ }^{8}$ This might be due to the difference in the sample size and age distribution. The commonest source of information of dual contraception was friends, which is comparable to the trend of sources of information on contraception in some studies among undergraduates in Nigeria and Tanzania. ${ }^{8}{ }^{810-12}$ This reflects the reason for the lower level 
of the knowledge of dual contraception compared to the high awareness in this study because the health workers who are more likely to educate the participants rightly on dual contraception were not the main source of information but only accounted for $6.3 \%$.

The study found that about two-fifths of the participants had used dual contraception despite the fact that majority of them are sexually active. This finding is in line with other studies showing low use of condoms or dual contraception by sexually active women and that most young people are involved in risky sexual behaviors with little or no regard for STIs and unwanted pregnancies. ${ }^{13,14}$

The prevalence of $41.6 \%$ for dual contraception found in this study corroborates the report of National Demographic Health Survey 2013 for women aged 15-24 years as well as the report among African-American adolescents. ${ }^{4,15}$ This finding is justifiably higher than reports of $2.6 \%-28.8 \%$ reported in other countries where studies on dual contraception were restricted to communities, STI clinics, or among HIV seropositive clients. ${ }^{16-19}$ Among African-American adolescents, the prevalence was also found to be $40 \%$, similar to the finding of this study. ${ }^{15}$

Condom was the most commonly used contraception among those who use single contraception, which was also found in other studies among undergraduates. ${ }^{8,20}$ However, in view of condom being the most commonly used contraception among the participants, there is a need to build on this by educating and motivating the young women on the efficacy of dual contraception so as to promote its use.

Female students with previous history of unwanted pregnancy and STIs are more likely to use dual contraception showing that they are aware of their risky sexual behavior and ways of preventing its associated complications. This corresponds with other studies that showed that adolescents who are concerned about acquiring STIs and unwanted pregnancy are more likely to use dual method. ${ }^{10,21,22}$ Brown et $\mathrm{al}^{15}$ reported that adolescents are less likely to use contraception or more likely to use less effective contraceptive methods if they believe their partners pose low risk to STI acquisition. In view of this, an appropriate education of young women on sexual and reproductive health issues with the availability of youth friendly reproductive health clinic will further promote the knowledge, awareness, and use of dual contraception.

In a similar pattern to earlier report, history of multiple sexual partners significantly influences the decision to use dual contraception. ${ }^{23}$
The study has provided information about the awareness and practice of dual contraception and some factors that influence its use among the female undergraduate students in the studied institutions. These can be used to develop sexual and reproductive educational programs to promote the knowledge and use of dual contraception as a means of preventing both pregnancy and STIs.

Our study was limited in information extraction for HIV status as many were unwilling to disclose such. In addition, consistent and inconsistent use of dual contraception was not evaluated.

\section{Conclusion}

There is good knowledge but low uptake of dual contraception among the students with perception of higher risk of pregnancy and STIs. There is a need to increase the awareness and knowledge as well as promote the consistent use of dual contraception among female undergraduates who are significantly at risk of unwanted pregnancy and STIs so as to reduce the incidence of unwanted pregnancy, unsafe abortion, and STIs.

\section{Author contributions}

OOB conceived the study. All authors contributed toward data analysis, drafting and critically revising the paper and agree to be accountable for all aspects of the work.

\section{Disclosure}

The authors report no conflicts of interest in this work.

\section{References}

1. Ngubane N, Patel D, Newell ML, et al. Messages about dual contraception in areas of high HIV prevalence are not heeded. S Afr Med J. 2008;98(3):209-212.

2. Ogbuji CO. Knowledge about HIV/AIDS and sexual practice among university of Ibadan students. Afr J Med Sci. 2005;34(1): $25-31$.

3. Orji EO, Adegbenro CA, Olalekan AW. Prevalence of sexual activity and family-planning use among undergraduates in Southwest Nigeria. Eur J Contracept Reprod Health Care. 2005;10(4):255-260.

4. Iyaniwura CA, Salako AA. Sexual activity and condom use by inschool youths in Sagamu, Ogun State. Niger Med Pract. 2005;48(4): 103-107.

5. National Population Commission (NPC) [Nigeria] and ICF International. Nigeria Demographic and Health Survey 2013. Abuja, Nigeria, and Rockville, Maryland: NPC and ICF International; 2014.

6. Cates WJ. The epidemiology and control of sexually transmitted diseases in adolescents. Adolesc Med State Art Rev. 1990;1(3):409-427.

7. Wong LP, Atefi N, Majid HA, Su TT. Prevalence of pregnancy experiences and contraceptive knowledge among single adults in a low socio-economic suburban community in Kuala Lumpur, Malaysia. BMC Public Health. 2014;14(suppl 3):S1. 
8. Somba MJ, Mbonile M, Obure J, Mahande MJ. Sexual behavior, contraceptive knowledge and use among female undergraduates' students of Muhimbili and Dar es Salaam Universities, Tanzania: a cross-sectional study. BMC Womens Health. 2014;14:94.

9. Chibwesha CJ, Li MS, Matoba CK, et al. Modern contraceptive and dual method use among HIV-infected women in Lusaka, Zambia. Infect Dis Obstet Gynecol. 2011;2011:261453,1-8.

10. Abiodun OM, Balogun OR. Sexual activity and contraceptive use among young female students of tertiary educational institutions in Ilorin, Nigeria. Contraception. 2009;79(2):146-149.

11. Arowojolu AO, Ilesanmi AO, Roberts OA, Okunlola MA. Sexuality, contraceptive choice and AIDs awareness among Nigerian undergraduates. Afr J Reprod Health. 2002;6(2):60-70.

12. Duru CB, Iwu AC, Diwe KC, et al. Sexual behaviour, contraceptive knowledge and use among female undergraduates in tertiary institutions in Imo State, Nigeria. Am J Med Sci Med. 2015;5(2):61-66.

13. Morroni C, Tibazarwa K, Myer L. Combined condom and contraceptive use among South African women. S Afr Med J. 2006;96(7): 620-622.

14. Rehle T, Shisana O, Pillay V, Zuma K, Puren A, Parker W. National HIV incidence measures - new insights into the South African epidemic. $S$ Afr Med J. 2007;97(3):194-197.

15. Brown JL, Hennessy M, Sales JM, et al. Multiple method contraception use among African American adolescents in four US cities. Infect Dis Obstet Gynecol. 2011;2011:765917.
16. Crosby RA, DiClemente RJ, Wingood GM, et al. Correlates of using dual methods for sexually transmitted diseases and pregnancy prevention among high-risk African American female teens. J Adolesc Health. 2001;28(5):410-414.

17. Santelli JS, Davis M, Celentano DD, Crump AD, Burwell LG. Combined use of condoms with other contraceptive methods among inner-city Baltimore women. Fam Plann Perspect. 1995;27(2):74-78.

18. Godeau E, Gabhainn SN, Vignes C, Ross J, Boyce W, Todd J. Contraceptive use by 15 -year-old students at their last sexual intercourse: results from 24 countries. Arch Pediatr Adolesc Med. 2008;162(1):66-73.

19. Lawani LO, Onyebuchi AK, Iyoke CA. Dual method use for protection of pregnancy and disease prevention among HIV-infected women in South East Nigeria. BMC Womens Health. 2014;14(1):39.

20. Alabi BO. Rampant sexual intercourse among female undergraduates in Nigeria and induced abortion related morbidity. J Studies Soc Sci. 2014;8(1):61-80.

21. Harvey SM, Henderson J, Branch M. Protecting against both pregnancy and disease: predictors of dual method use among a sample of women. Women Health. 2004;39(1):25-43.

22. Ott MA, Adler NE, Millstein SG, Tschann JM, Ellen JM. The trade-off between hormonal contraceptives and condoms among adolescents. Perspect Sex Reprod Health. 2002;34(1):6-14.

23. MacPhail C, Pettifor AE, Pascoe S, Rees HV. Contraceptive use and pregnancy among 15-24 year old South African women: a nationally representative cross-sectional survey. BMC Med. 2007;5:31. 


\section{Supplementary material Questionnaire}

1) BIODATA

a. Age (in years):

b. Marital status: Cohabiting $\square$ Single $\square$ Married $\square$ Separated $\square$ Divorced $\square$

ii. If married, type of marriage: Monogamy $\square$ Polygamy $\square$

c. Religion: Islam $\square$ Christianity $\square$ Traditional $\square$ Others $\square$

d. Tribe: Yoruba $\square$ Hausa $\square$ Igbo $\square$ Others $\square$

2) Have you heard of contraception (family planning methods) before?

Yes $\square \mathrm{No} \square$

3) Do you approve of contraception?

Yes $\square$ No $\square$

4) Have you ever used any contraceptive method before?

Yes $\square$ No $\square$

If No, why not?.

If Yes, (i) when did you first use contraception?

Age ....... years

(ii) what type of contraception did you use?

a) Barrier method: Condom $\square$ Diaphragm $\square$ Cervical

cap $\square$

b) Injectable (injections): Depo Provera $\square$

c) Daily oral contraceptive pills $\square$

d) IUD inserted into your womb (intrauterine contraceptive device) $\square$

e) "Morning-after" (after sex) pills, like Postinor $\square$

f) Implant inserted into your arm (Jadelle, Implanon, Norplant) $\square$

g) Sterilization (bilateral tubal ligation) $\square$

5) Are you currently using any contraception?

Yes $\square$ No $\square$

If No, why not?

If Yes, which one(s) do you use currently?

(You can tick more than one)

a) Barrier method: Condom $\square$ Diaphragm $\square$ Cervical cap $\square$

b) Injectable: Depo-Provera $\square$

c) "Morning-after" (after sex) pills, like Postinor $\square$

d) Oral contraceptive pills $\square$

e) IUD (intrauterine contraceptive device) $\square$

f) Implant (Jadelle, Implanon, Norplant) $\square$

g) Sterilization (bilateral tubal ligation) $\square$

6) Have you heard of dual contraception

(using two contraceptive methods - condom + any other

one mentioned above in number $4 \mathrm{~b}-4 \mathrm{~g}$ )

Yes $\square$ No $\square$
7) What is your source of information of dual

contraception:

Radio $\square$

Television $\square$

Newspaper $\square$

Friends/colleagues $\square$

Health worker $\square$

Teachers/educators $\square$

Chemist/pharmacy $\square$

Religious groups $\square$

8) Dual contraception prevents (Tick the most suitable):

Unwanted pregnancy only $\square$

Sexually transmitted infection only $\square$

HIV only $\square$

Both pregnancy and sexually transmitted infections $\square$

I don't know $\square$

9) Do you practice dual contraception?

Yes $\square$ No $\square$

If No, why not?

If Yes, which ones do you use?

a) Condom + injectable contraceptives $\square$

b) Condom + oral contraceptive pills $\square$

c) Condom + IUD $\square$

d) Condom + implant $\square$

e) Condom + sterilization/BTL

10) What is your HIV status?

Negative $\square$ Positive $\square$ Not known $\square$

Sexual practices

11) Have you ever had sex?

Yes $\square$ No $\square$

If yes, when did you first had sexual intercourse?

Age ....... Years

12) Have you had sexual intercourse in the past 6 months? Yes $\square$ No $\square$

13) How many sexual partners have you had in the past

12 months? ......

14) Did you use contraception in your last sexual intercourse?

Yes $\square$ No $\square$

a. If yes, did you use

i) Single contraception $\square$

ii) Dual contraception $\square$

Please state the type of contraception(s) you used in your last sexual intercourse

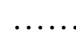


b. If yes to question 14 , what is your principal reason for using contraception

$\ldots \ldots \ldots \ldots \ldots \ldots \ldots \ldots \ldots \ldots \ldots \ldots \ldots \ldots$

15) Have you ever had an unwanted or unplanned pregnancy
Yes $\square$ No $\square$

16) Have you been treated for sexually transmitted infections like Chlamydia, Gonorrhea, herpes, Syphilis in the past 12 months (the symptoms you will present with could include offensive vaginal discharge, lower abdominal pain, perineal sores or ulcer, vulva itching, painful sex)

Yes $\square$ No $\square$
Open Access Journal of Contraception

\section{Publish your work in this journal}

Open Access Journal of Contraception is an international, peerreviewed, open access, online journal, publishing original research, reports, reviews and commentaries on all areas of contraception. In addition to clinical research, demographics and health-related aspects, the journal welcomes new findings in animal and preclinical studies

Submit your manuscript here: https://www.dovepress.com/open-access-journal-of-contraception-journal

relating to understanding the biological mechanisms and practical development of new contraceptive agents. The manuscript management system is completely online and includes a very quick and fair peer-review system. Visit http://www.dovepress.com/testimonials.php to read real quotes from published authors. 